\title{
Elevated MMP-12 protein levels in induced sputum from patients with COPD
}

\author{
I K Demedts, A Morel-Montero, S Lebecque, Y Pacheco, D Cataldo, G F Joos, \\ R A Pauwelst, G G Brusselle

See end of article for authors' affiliations

.....................

Correspondence to: Dr I K Demedts,

Department of Respiratory

Diseases, Ghent University

Hospital 7K12-IE, De

Pintelaan 185, B-9000

Ghent, Belgium;

M.DemedtslngelK@

UGent.be

Received 15 April 2005

Accepted

21 November 2005

Published Online First

24 November 2005
Background: Several matrix metalloproteinases (MMPs) are involved in the pathogenesis of chronic obstructive pulmonary disease (COPD). In mice, MMP-12 plays a crucial role in the development of cigarette smoke induced emphysema. A study was undertaken to investigate the role of MMP-12 in the development of COPD in human smokers.

Methods: Induced sputum samples were collected from patients with stable $\operatorname{COPD}(n=28)$, healthy smokers $(n=14)$, never smokers $(n=20)$, and former smokers $(n=14)$. MMP-12 protein levels in induced sputum were determined by ELISA and compared between the four study groups. MMP-12 enzymatic activity in induced sputum was evaluated by casein zymography and by cleaving of a fluorescence quenched substrate.

Results: Median (IQR) MMP-12 levels were significantly higher in COPD patients than in healthy smokers, never smokers, and former smokers $(17.5(7.1-42.1)$ v $6.7(3.9-10.4)$ v $4.2(2.4-11.3)$ v 6.1 (4.5$7.6) \mathrm{ng} / \mathrm{ml}, \mathrm{p}=0.0002$ ). MMP-12 enzymatic activity was significantly higher in patients with COPD than in controls $(4.11(1.4-8.0) \vee 0.14(0.1-0.2) \mu \mathrm{g} / \mu \mathrm{l}, \mathrm{p}=0.0002)$.

Conclusion: MMP-12 is markedly increased in induced sputum from patients with stable COPD compared with controls, suggesting a role for MMP-12 in the development of COPD in smokers.

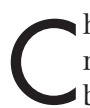
hronic obstructive pulmonary disease (COPD) is a major health problem and it is predicted that it will be the third most common cause of death worldwide by 2020. ${ }^{1}$ The disease is mainly caused by cigarette smoking which leads to chronic inflammation of the airways and parenchymal destruction resulting in emphysema. The destruction of lung tissue is caused by an imbalance between protease and antiprotease activity, where the excess of proteolytic enzymes such as matrix metalloproteinases (MMPs), cysteine, and serine proteinases is insufficiently counterbalanced by a rise in antiproteolytic molecules. ${ }^{2}$

Matrix metalloproteinases are a family of metalloproteases that contain a zinc atom at their active site and are able to degrade matrix macromolecules including collagen, laminin, and elastin. ${ }^{3}$ In addition to their ability to degrade extracellular matrix components, some MMPs also cleave cytokines $^{4}$ and antiproteolytic molecules. ${ }^{5-7}$

An understanding of the functional activity of MMPs and the fact that MMPs such as MMP-9 and MMP-12 were found in alveolar macrophages ${ }^{8} 9$ led to the hypothesis that these enzymes could play a role in the destruction of lung parenchyma induced by cigarette smoke. More specifically, there is convincing evidence from animal models that MMP12 is crucial in the development of smoke induced emphysema. MMP-12 knock out mice were completely protected from development of emphysema despite long term smoke exposure, while wild type mice developed alveolar space enlargement. ${ }^{10}$ In addition, MMP-12 knock out mice had impaired recruitment of monocytes into the lung, possibly due to the loss of MMP-12 mediated generation of elastin fragments (chemotactic for monocytes).

The contribution of MMP-12 to smoke induced emphysema is probably not limited to a direct effect (destruction of extracellular matrix) but is almost certainly enhanced by indirect effects such as inactivation of $\alpha_{1}$-antitrypsin by MMP- $12^{11}$ and MMP-12 mediated recruitment of neutrophils (which in their turn are able to release proteolytic enzymes) to the lung in response to cigarette smoke. ${ }^{4}$

Altogether, these data suggest a pivotal role for MMP-12 in the development of smoke induced emphysema in mice. However, in human subjects the role of MMP-12 in the development of COPD is still unclear. Very few studies have investigated the involvement of MMP-12 in cigarette smoke induced lung damage in human subjects, partly because of the lack of appropriate diagnostic tools to detect the MMP-12 protein in sputum, bronchoalveolar lavage (BAL) fluid or lung tissue. One group found an association between polymorphisms in the MMP-12 gene and the rate of decline of lung function in smokers, which suggests a role for MMP12 in the pathogenesis of COPD. ${ }^{12}$ Molet and colleagues recently reported increased MMP-12 levels in BAL fluid (demonstrated by Western blot analysis), BAL cells, and bronchial biopsy tissue from COPD patients compared with controls. ${ }^{13}$

To explore the contribution of MMP-12 to the development of COPD in smokers, induced sputum samples were collected from never smokers, healthy smokers (smokers without airway obstruction), former smokers (quit smoking for more than 1 year), and patients with stable COPD and the MMP12 levels in the induced sputum samples in the four groups were compared.

Abbreviations: BAL, bronchoalveolar lavage; COPD, chronic obstructive pulmonary disease; DTT, dithiotreitol; ECM, extracellular matrix; ELISA, enzyme linked immunosorbent assay; $F_{1} V_{1}$, forced expiratory volume in 1 second; FVC, forced vital capacity; GOLD, Global Initiative for Chronic Obstructive Lung Disease; ICS, inhaled corticosteroids; IFN- $\gamma$, interferon- $\gamma$; IL-13, interleukin-13; MMP, matrix metalloproteinase; PBS, phosphate buffered saline; TGF- $\beta_{1}$, transforming growth factor $\beta_{1}$; TNF- $\alpha$, tumour necrosis factor $\alpha$

† Deceased 3 January 2005 


\section{METHODS}

\section{Subjects}

Seventy six subjects participated in the study and were classified in four groups: COPD stage I (mild) to II (moderate) patients according to the GOLD (Global Initiative for Chronic Obstructive Lung Disease) criteria (www.goldcopd.com), never smokers, healthy smokers, and former smokers (subjects who quit smoking for more than a year with a smoking history of at least 10 pack years). Patients were recruited from our outpatient pulmonary clinic while controls were recruited by advertising as well as from the outpatient clinic. All patients with COPD had stable disease; patients with symptoms or clinical signs of a COPD exacerbation in the preceding 2 months were excluded. For safety reasons, patients suffering from severe and very severe COPD (GOLD stage III-IV) were excluded, as were subjects with asthma, bronchiectasis, or a respiratory infection in the preceding 4 weeks. Written informed consent was obtained from all subjects according to protocols approved by the medical ethical committee of the Ghent University Hospital.

\section{Sputum induction and processing}

Sputum induction was performed as described previously ${ }^{14}$ by inhalation of sterile, pyrogen-free, hypertonic saline at increasing concentrations ( $\mathrm{NaCl} 3 \%, 4 \%$, and $5 \%$, respectively) over a 5 minute period after the inhalation of salbutamol $(2 \times 200 \mu \mathrm{g})$. The hypertonic saline was nebulised via an ultrasonic nebuliser (Ultra-Neb; Devilbiss Health Care Inc, Somerset, PA, USA). Each time after the inhalation of a specific saline concentration, subjects were encouraged to cough and expectorate an adequate sample. Spirometric values were obtained before and after induction by means of a water sealed spirometer (Vmax 20C, Sensormedics, Yorba Linda, CA, USA). Processing of induced sputum was performed as previously described. ${ }^{15}$ To reduce salivary contamination, sputum plugs were selected and transferred in a polystyrene tube. A freshly prepared $0.1 \%$ solution of dithiotreitol (DTT; 10\% Sputalysin, Boehringer-Calbiochem Corp, San Diego, CA, USA) was added in an amount equal to four times the weight of the sputum plugs. The tube was vortex mixed for 30 seconds and the sputum was incubated on a tube rocker for 15 minutes at room temperature. An amount of phosphate buffered saline (PBS) equal to the DTT volume was then added and the sample was incubated for a further 5 minutes. The sample was filtered through a $70 \mu \mathrm{m}$ cell strainer (Becton Dickinson Labware, NJ, USA) and



Figure 1 Autoradiography of SDS gel electrophoresis without (lane 1) or with (lane 2) $\beta$-mercaptoethanol of MMP12-transfected COS7 cells supernatant radiolabelled with ${ }^{35} \mathrm{~S}$. Immunoprecipitation of COS7 supernatant with monoclonal antibodies 701E4.03 (lane 3) and 706F9.01 (lane 4). centrifuged at $390 \mathrm{~g}$ for 10 minutes. The supernatant was aspirated, aliquoted, and stored at $-80^{\circ} \mathrm{C}$. The cell pellet was resuspended in PBS supplemented with $2 \%$ human serum albumin (Behring Diagnostics, San Jose, CA, USA); cells were counted in a haemocytometer and the cell concentration was adjusted to $0.7 \times 10^{6}$ cells $/ \mathrm{ml}$. Cytospins were prepared by adding $60 \mu \mathrm{l}$ of cell suspension into Shandon II cytocentrifuge cups (Shandon Southern Instruments, Sewickley, PA, USA) and spun for 5 minutes at $300 \mathrm{rpm}$. Two slides were stained with May-Grünwald-Giemsa for an overall count of leucocytes, bronchial epithelial cells, and squamous cells. Slides were counted blind by two investigators. For cell differentiation, 400 nucleated cells per slide were counted and expressed as the percentage of intact round nucleated cells, excluding squamous epithelial cells.

\section{Generation of antibodies against MMP- 12}

MMP-12 protein was detected in induced sputum supernatant using an enzyme linked immunosorbent assay developed in cooperation with industrial partners (Immunotech, Marseille, France and Schering-Plough LIR, Dardilly, France). Antibodies were generated as follows: the full length MMP-12 cDNA was cloned from a cDNA library constructed from CD34-derived dendritic cells. The clone was entirely sequenced and shown to correspond to the published sequence. ${ }^{9}$ The MMP-12 cDNA was cloned in PME18S vector that was electroporated in COS7 cells. Enriched supernatant was used to immunise Balb/C mice. Hybridomas $(n=23)$ were obtained as previously described ${ }^{16}$ and screened by immunostaining of COS7 transfected cells. Their specificity was confirmed by Western blot analysis and by immunoprecipitation of radiolabelled recombinant MMP-12 (fig 1).

\section{Development of ELISA for MMP-12 detection}

Selection for ELISA was performed by testing the 23 antibodies obtained. The most sensitive ELISA used antibody 701E4.03 for capture and antibody 706F9.01 for detection of MMP-12. Recombinant MMP-12 was immunopurified with a third antibody, 603.E6.

Recombinant human MMP-12 with known concentrations was used as standard. MMP-12 in sputum supernatant was quantified by converting the optical density values of the samples to nanograms from the standard curve obtained with recombinant MMP-12. Sensitivity of the ELISA was less than $50 \mathrm{pg} / \mathrm{ml}$. Specificity testing showed that there was no detection of other related MMPs (fig 2) including MMP-1, MMP-3 and MMP-9 (R\&D Systems, Abingdon, UK) with the ELISA for MMP-12 (kindly provided by Immunotech). Mean intrabatch coefficient of variation of the ELISA was less than $6 \%$.

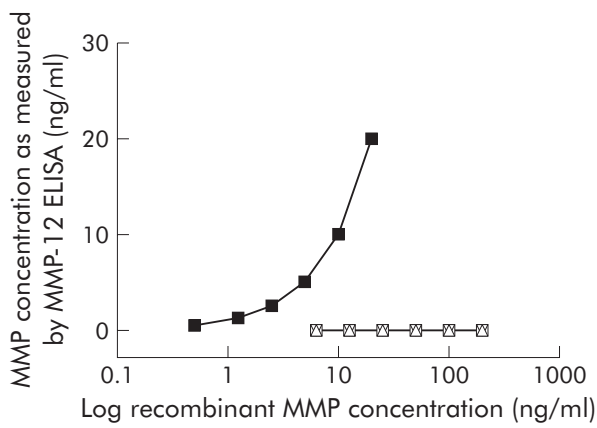

Figure 2 Specificity of the ELISA for MMP-12. Detection of a serial dilution of recombinant MMP-12 protein by the ELISA ( $\mathbf{\square})$. No recombinant MMP-1 $(\triangle), M M P-3(\nabla)$, or MMP-9 $(\square)$ were detected with the ELISA, even at high concentrations. 


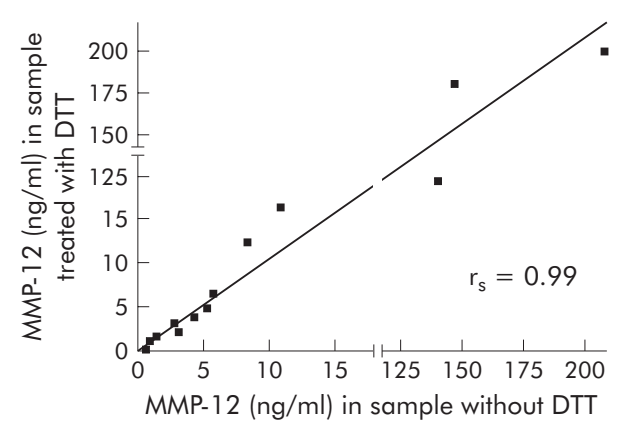

Figure 3 Effect of dithiotreitol (DTT) on the detection of MMP-12 in sputum. Aliquots from the same sputum sample were processed with or without DTT. There was a strong positive correlation $\left(r_{\mathrm{s}}=0.99\right.$; $p=0.000001$ ) between the MMP-12 levels in aliquots treated with DTT and the corresponding aliquots processed without DTT. DTT therefore has no effect on the detection of MMP-12 in sputum samples.

Since the use of dithiotreitol (DTT) in sputum processing could possibly interfere with the detection of MMP-12 in sputum samples, we compared MMP-12 levels in sputum samples treated or untreated with DTT. Sputum samples were divided into two aliquots: one aliquot was treated with DTT (concentration matching the concentration used in the standard procedure as described above), while PBS was added to the other aliquot instead of DTT. Both samples were then centrifuged $\left(50000 \mathrm{~g}, 4^{\circ} \mathrm{C}, 90\right.$ minutes) in an ultracentrifuge (Ultracentrifuge Floor Model L5-65, Beckman Coulter, Fullerton, CA, USA) and sputum supernatant was stored at $-80^{\circ} \mathrm{C}$. The levels of MMP- 12 measured by the ELISA were compared between the two aliquots. There was no difference in MMP-12 levels between these two methods $(n=13$, $\mathrm{p}=0.89$ ). Moreover, there was a strong positive correlation $\left(r_{\mathrm{s}}=0.99 ; \mathrm{p}=0.000001\right)$ between MMP-12 levels in both aliquots from the same sample (fig 3), so we concluded that DTT has no influence on the detection of MMP-12 in sputum samples.

\section{Zymography}

Casein zymography was performed based on a previously described technique with slight modifications. ${ }^{17}$ Ten $\mu \mathrm{l}$ of sputum supernatant were mixed with the same amount of non-reducing sample buffer. Electrophoresis was carried out on a sodium dodecyl sulfate (SDS)-10\% polyacrylamide gel containing $\alpha$-casein (Sigma) at a concentration of $1 \mathrm{mg} / \mathrm{ml}$. Gels were then incubated in $2.5 \%(\mathrm{v} / \mathrm{v})$ Triton X-100 for 30 minutes and soaked for 16 hours in a buffer containing $10 \mathrm{mM} \mathrm{CaCl}_{2}$ and $100 \mathrm{mM} \mathrm{NaCl}$ at $37^{\circ} \mathrm{C}$. The gels were then stained with Coomassie brillant blue G250. Caseinolytic activity was detected as white lysis zones against a blue background. Quantitative evaluation of the gelatinolytic activity was performed by scanning the gel using a Bio-Rad Multilmager imaging densitometer. Recombinant MMP-12 (R\&D Systems, Abingdon, UK) was used to confirm the validity of the procedure and bands obtained with rMMP-12 were used as standards. Caseinolytic activity was determined by scanning the lysis band in the area corresponding to rMMP-12.

\section{MMP-12 activity assessed by fluorescence quenched substrate cleaving}

In addition to casein zymography, MMP-12 specific enzymatic activity was analysed using a technique based on the EnzoLyte 490 kit (AnaSpec, San Jose, CA, USA) which was slightly modified. This kit is optimised to detect the activity of MMP-12 in biological samples using a fluorescence quenched substrate (EDANS/DabcylPlusTM FRET peptide). Upon cleavage into two separate fragments by MMPs, the fluorescence of this peptide is recovered and can be monitored at excitation/emission wavelengths of $340 \mathrm{~nm} /$ $490 \mathrm{~nm}$. Sputum samples were incubated with $1 \mathrm{mM} \mathrm{4-}$ aminophenylmercuric acetate (APMA) for 1 hour to activate MMP-12. $50 \mu \mathrm{l}$ of the sample were incubated in a 96 well plate. The plate was incubated at room temperature for 45 minutes and protected from light. Stop solution from Anaspec $(50 \mu \mathrm{l})$ was added to each well and the fluorescence intensity was measured at $490 \mathrm{~nm}$ after excitation at $340 \mathrm{~nm}$. MMP-12 purified enzyme used as positive control was purchased from Sigma (St Louis, Missouri, USA).

\section{Analysis of data}

Statistical analysis was performed with SPSS Version 12.0 for Windows. Data are presented as median (IQR) and statistical analysis was performed using non-parametric testing with Kruskal-Wallis tests. Significant differences between groups were further investigated by Mann-Whitney $U$ testing. Spearman's rank correlation was calculated to assess the correlation between MMP-12 levels, lung function parameters, and cell differential counts in induced sputum of study subjects. Statistical significance was defined as $\mathrm{p}<0.05$.

\section{RESULTS}

\section{Subject characteristics}

Twenty eight patients with stable COPD (no exacerbation in the preceding 2 months) were included in the study (table 1). Four were classified as COPD GOLD stage I while 24 had a disease severity of GOLD stage II. Seventeen of the COPD patients took inhaled steroids and 11 did not; 14 were active smokers and 14 had quit smoking for more than 1 year. Twenty never smokers, 14 healthy smokers, and 14 former smokers were studied in the control groups. All healthy subjects had normal spirometric values. The characteristics of the four study groups are summarised in table 1. Forced expiratory volume in 1 second $\left(\mathrm{FEV}_{1}\right)$ and the $\mathrm{FEV}_{\mathrm{l}} / \mathrm{FVC}$ ratio were significantly lower in patients with COPD than in the control groups.

\section{Differential cell counts of induced sputum}

Total and differential cell counts of induced sputum are shown in table 2. The total inflammatory cell number in induced sputum was significantly higher in patients with COPD than in smokers without airway obstruction. The percentage of macrophages was lower in the sputum of COPD patients than in never smokers and active smokers, while absolute numbers of macrophages in induced sputum were not significantly different between the groups. Induced sputum from COPD patients contained significantly more neutrophils than induced sputum from never smokers and active smokers (table 2 ).

\section{MMP- 12 protein in induced sputum}

MMP-12 protein could be detected by ELISA in all induced sputum samples (fig 4). Patients with COPD had significantly higher levels of MMP-12 in induced sputum (median $17.5 \mathrm{ng} / \mathrm{ml}$ (IQR 7.1-42.1)) than never smokers $(4.2 \mathrm{ng} / \mathrm{ml}$ (2.4-11.3)), "healthy" smokers (6.7 ng/ml (3.9-10.4)), and former smokers $(6.1 \mathrm{ng} / \mathrm{ml}(4.5-7.6))$. There was no significant difference in MMP-12 levels between the three control groups. MMP-12 levels in induced sputum from COPD patients who were active smokers (16.1 ng/ml (5.847.2)) did not differ significantly from those in COPD patients who had quit smoking (18.2 ng/ml (10.1-38.9), $\mathrm{p}=0.87$ ). There was no difference in the level of MMP-12 protein in sputum from COPD patients who were taking inhaled corticosteroids $(14.8 \mathrm{ng} / \mathrm{ml}(6.8-28.2))$ and those 
Table 1 Characteristics of study subjects

\begin{tabular}{|c|c|c|c|c|}
\hline & $\begin{array}{l}\text { COPD } \\
(n=28)\end{array}$ & $\begin{array}{l}\text { Never smokers } \\
(\mathrm{n}=20)\end{array}$ & $\begin{array}{l}\text { Smokers } \\
(n=14)\end{array}$ & $\begin{array}{l}\text { Former smokers } \\
(n=14)\end{array}$ \\
\hline Sex ratio $(M / F)$ & $24 / 4$ & $4 / 16$ & $7 / 7$ & $7 / 7$ \\
\hline Age (years) & $64.0(52-72)^{*}+\ddagger$ & $52.5(42-56)$ & $51.0(49-53)$ & $52.5(46-63)$ \\
\hline Smoking history (pack years) & $42.0(26-55) \pm \S$ & $0.0(0-0)$ & $35.0(16-43)$ & $30.0(9-42)$ \\
\hline $\mathrm{FEV}_{1}(\mathrm{I})$ & $2.0(1.7-2.3)$ & $3.0(2.7-3.4)$ & $3.0(2.5-3.3)$ & $3.4(2.7-3.7)$ \\
\hline $\mathrm{FEV}_{1}$ (\% predicted) & $70.0(63-78)$ & $105.5(97-118)$ & $96.0(91-101)$ & $108.0(100-113$ \\
\hline $\mathrm{FEV}_{1} / \mathrm{FVC}(\%)$ & $56.0(49-65)$ & $80.5(77-83)$ & $78.0(73-82)$ & $78.5(75-80)$ \\
\hline Bronchodilators $(\mathrm{Y} / \mathrm{N})$ & $20 / 8$ & $0 / 20$ & $0 / 14$ & $0 / 14$ \\
\hline $\mathrm{ICS}(\mathrm{Y} / \mathrm{N})$ & $17 / 11$ & $0 / 20$ & $0 / 14$ & $0 / 14$ \\
\hline
\end{tabular}

FEV 1 , forced expiratory volume in 1 second; FVC, forced vital capacity; ICS, inhaled corticosteroids.

Data are presented as median (IQR).

${ }^{*} \mathrm{p}<0.01 v$ never smokers; $\mathrm{p} p<0.001 v$ smokers; $\ddagger \mathrm{p}<0.05 v$ former smokers; $\$ p<0.001 v$ never smokers; $9 p<0.001 v$ never smokers, smokers and former smokers.

who were not on inhaled corticosteroids $(25.8 \mathrm{ng} / \mathrm{ml}(15.4-$ 72.8), $\mathrm{p}=0.21$ ).

\section{Zymography}

To evaluate MMP-12 enzymatic activity, a number of sputum supernatants samples were analysed by casein zymography (seven patients with COPD, five healthy smokers). As shown in fig 5A, functionally active MMP-12 could be detected in most samples from COPD patients but not in samples from healthy smokers. The relative degree of enzymatic activity was calculated as described above (fig 5B). There was a strong positive correlation between the amount of MMP-12 detected by the ELISA and the degree of enzymatic activity as evaluated by casein zymography $\left(r_{\mathrm{s}}=0.9 ; \mathrm{p}=0.01\right)$.

\section{MMP-12 activity assessed by fluorescence quenched substrate cleaving}

In addition to casein zymography, MMP-12 specific enzymatic activity was analysed by cleavage of a fluorescence quenched substrate. For this purpose, 10 samples from COPD patients were analysed and compared with 10 control samples (five smokers, three never smokers, and two former smokers). MMP-12 specific activity was significantly higher in COPD patients than in controls $(4.11(1.4-8.0) v 0.14(0.1-$ $0.2) \mu \mathrm{g} / \mu \mathrm{l}, \mathrm{p}=0.0002)$. There was a strong positive correlation between the degree of MMP-12 enzymatic activity and the amount of MMP-12 detected by the ELISA $\left(r_{\mathrm{s}}=0.79\right.$; $\mathrm{p}=0.00002$ ).

\section{Correlations between sputum MMP-12 and clinical and inflammatory parameters}

An inverse correlation was found between MMP-12 protein levels in induced sputum and the $\mathrm{FEV}_{\mathrm{l}} / \mathrm{FVC}$ ratio $\left(r_{\mathrm{S}}=-0.44\right.$, $\mathrm{p}=0.00007)$ as well as the degree of airway obstruction $\left(r_{\mathrm{s}}=-0.38, \mathrm{p}=0.0008\right)$ as measured by $\mathrm{FEV}_{1} \%$ when analysed for all subjects (fig 6). However, when correlation analysis was performed in each group separately, no significant correlations were found between MMP-12 protein levels and spirometric measurements. This suggests that the observed correlation resulted from the differences between the groups rather than representing a true association.

There was no correlation between MMP-12 levels and the absolute number of macrophages, lymphocytes or eosinophils, while there was a positive correlation between MMP-12 and the absolute neutrophil counts $\left(r_{\mathrm{s}}=0.41, \mathrm{p}=0.0004\right)$ in induced sputum when analysed for all subjects (fig 7). However, when each group was analysed separately, a significant correlation between the MMP-12 protein level and absolute neutrophil number was found only in never smokers $\left(r_{\mathrm{s}}=0.64, \mathrm{p}=0.002\right)$.

\section{DISCUSSION}

This is the first study to report detection of MMP-12 at the protein level in induced sputum. Although several studies in animal models have suggested a possible role for MMP-12 in the development of COPD, very few data are available on the role of MMP-12 in human lung diseases, mainly because of the lack of appropriate diagnostic tools.

The major finding of this study was that the level of MMP12 in induced sputum was significantly higher in patients with mild to moderate COPD than in the control groups (never smokers, former smokers, and "healthy" smokers). These findings suggest that MMP-12 is involved (together with other proteolytic enzymes) in the development of COPD and confirms earlier findings from animal models. ${ }^{10}$

An interesting finding was the difference in the MMP-12 level in induced sputum from patients with COPD and "healthy" smokers; MMP-12 levels were clearly increased in COPD patients but not in smokers without airway obstruction. It therefore appears that MMP-12 is not induced in all smokers but only in those with COPD.

Table 2 Total and differential cell counts in induced sputum

\begin{tabular}{|c|c|c|c|c|}
\hline & $\begin{array}{l}\text { COPD } \\
(n=28)\end{array}$ & $\begin{array}{l}\text { Never smokers } \\
(n=20)\end{array}$ & $\begin{array}{l}\text { Smokers } \\
(n=14)\end{array}$ & $\begin{array}{l}\text { Former smokers } \\
(n=14)\end{array}$ \\
\hline Total inflammatory cells $\left(\times 10^{3} / \mathrm{mg}\right)$ & $14.0(8-21)^{*}$ & $6.5(5-15)$ & $5.6(4-8)$ & $10.8(8-18)^{*}$ \\
\hline Macrophages (\%) & $34.8(18-43)^{*} \dagger$ & $50.4(38-68) \ddagger$ & $52.3(30-66)$ & $36.6(24-52)$ \\
\hline Macrophages $\left(\times 10^{3} / \mathrm{mg}\right)$ & $4.0(2.1-6.4)$ & $3.9(2.9-5.1)$ & $2.3(1.8-3.5)$ & $4.2(2.6-5.6)$ \\
\hline Neutrophils (\%) & $61.5(56-75)^{*} \dagger$ & $48.0(27-59) \ddagger$ & $46.1(32-66)$ & $61.1(47-75)$ \\
\hline Neutrophils $\left(\times 10^{3} / \mathrm{mg}\right)$ & $9.1(4.5-15.0) \xi$ & $3.3(1.0-9.8)$ & $2.3(1.5-4.5) \ddagger$ & $6.3(3.9-13.0)$ \\
\hline Eosinophils (\%) & $1.5(0.5-3.1) \dagger$ & $0.2(0.0-0.7)$ & $1.0(0.6-1.6) \dagger$ & $0.5(0.0-1.8)$ \\
\hline Eosinophils $\left(\times 10^{3} / \mathrm{mg}\right)$ & $0.1(0.0-0.6) \dagger$ & $0.0(0.0-0.1)^{*}$ & $0.1(0.0-0.1)$ & $0.1(0.0-0.1)$ \\
\hline Lymphocytes (\%) & $0.5(0.2-1.3) \dagger$ & $1.4(0.9-2.9) \ddagger$ & $0.2(0.2-0.9) \dagger$ & $0.6(0.3-1.4)$ \\
\hline Lymphocytes $\left(\times 10^{3} / \mathrm{mg}\right)$ & $0.1(0.0-0.2)$ & $0.1(0.1-0.2)$ & $0.0(0.0-0.0) \dagger$ & $0.1(0.0-0.1)^{*}$ \\
\hline
\end{tabular}

Data are presented as median (IQR).

${ }^{*} \mathrm{p}<0.05 v$ smokers; $\uparrow \mathrm{p}<0.01 v$ never smokers; $\neq \mathrm{p}<0.05 v$ former smokers; $\S p<0.05 v$ never smokers; $9 p<0.01 v$ smokers. 


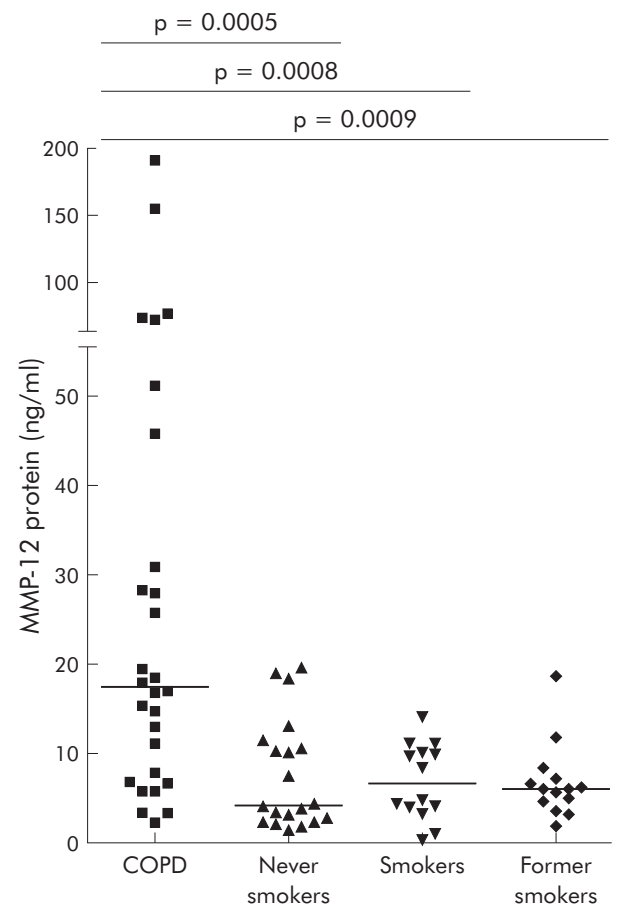

Figure 4 Elevated levels of MMP-12 protein in induced sputum from COPD patients $(n=28)$ compared with never smokers $(n=20)$, healthy smokers $(n=14)$, and former smokers $(n=14)$. Horizontal bars represent median values.

Importantly, MMP-12 levels were not only increased in COPD patients who were active smokers but also in those who had quit smoking. These data suggest that MMP-12 in sputum is not induced by cigarette smoking per se, but by the disease itself. However, while there was no statistically significant difference between COPD patients who had quit smoking and those who were current smokers, the mean MMP-12 levels were higher in the latter group which suggests an additional effect of cigarette smoking on MMP12 levels in induced sputum from patients with COPD. It is important to remember that only patients with mild to moderate COPD were included in this study; patients with severe and very severe COPD (GOLD stage III and IV) were excluded for safety reasons. Thus, in those patients with early stages of COPD, MMP-12 could be an important biomarker of the disease. However, there is some overlap between the lowest MMP-12 levels in COPD patients and the MMP-12 levels in controls. Measurement of MMP-12 in induced sputum as a screening test for COPD is therefore probably not useful. However, future studies in larger groups of subjects are needed to address this question.

The mechanism by which MMP-12 is induced in patients with COPD remains unclear. Data from animal models suggest that a local deficiency in transforming growth factor $\beta_{1}\left(\text { TGF }-\beta_{1}\right)^{18}$ or a rise in interleukin-13 (IL-13) $)^{19}$ or interferon- $\gamma(\text { IFN- } \gamma)^{20}$ leads to overproduction of macrophage MMP-12. Grumelli et $a l^{21}$ recently showed that, in human subjects, lung macrophages release MMP-12 in response to interferon inducible protein 10 (IP-10) and monokine induced by interferon (MIG), two chemokines that are secreted by lung macrophages and lymphocytes from patients with emphysema.

Alveolar macrophages appear to be the principal source of MMP-12 in the lung. ${ }^{913}$ However, recent data from in vitro studies suggest that MMP-12 can also be released by human bronchial epithelial cells in response to cigarette smoke. ${ }^{22}{ }^{23}$ Moreover, in vitro studies show a strong upregulation of
A
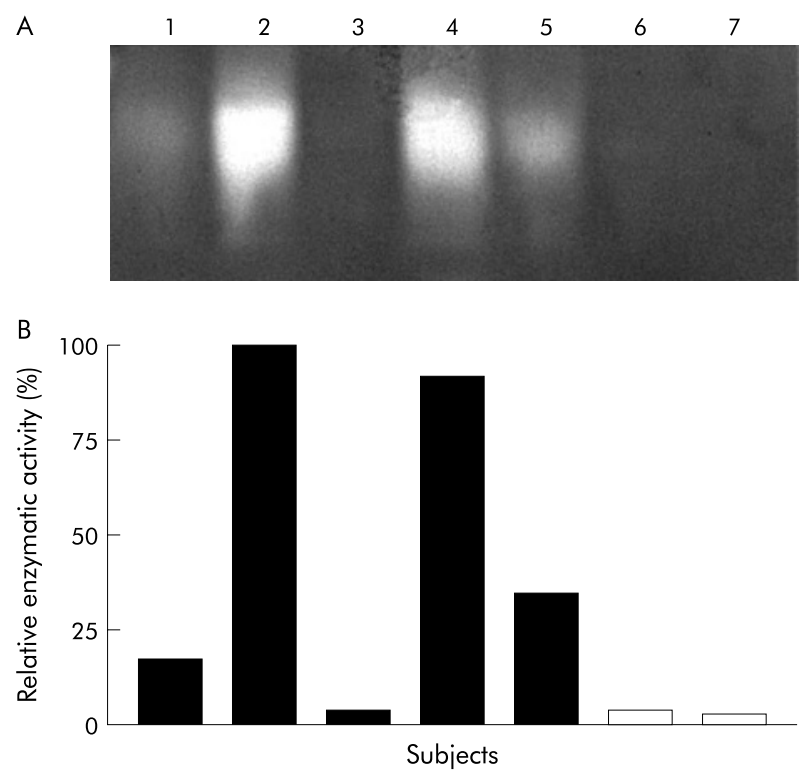

Figure 5 Detection of functionally active MMP- 12 by casein zymography. (A) Functionally active MMP-12 was present in sputum samples from four of five COPD patients (lanes 1-5), while no functionally active MMP-12 was detected in sputum from healthy smokers (lanes 6 and 7). (B) Relative enzymatic activity was highest in patients with COPD. Data shown are representative of 12 subjects (seven COPD patients, five healthy smokers). Black bars represent COPD patients, white bars represent healthy smokers.

MMP-12 transcription in immature monocyte derived dendritic cells (DC) during differentiation from monocytes into DC. ${ }^{24}$ So, whereas macrophages are probably the most important source of MMP-12, both bronchial epithelial cells and DC might contribute to the total amount of MMP-12 in human
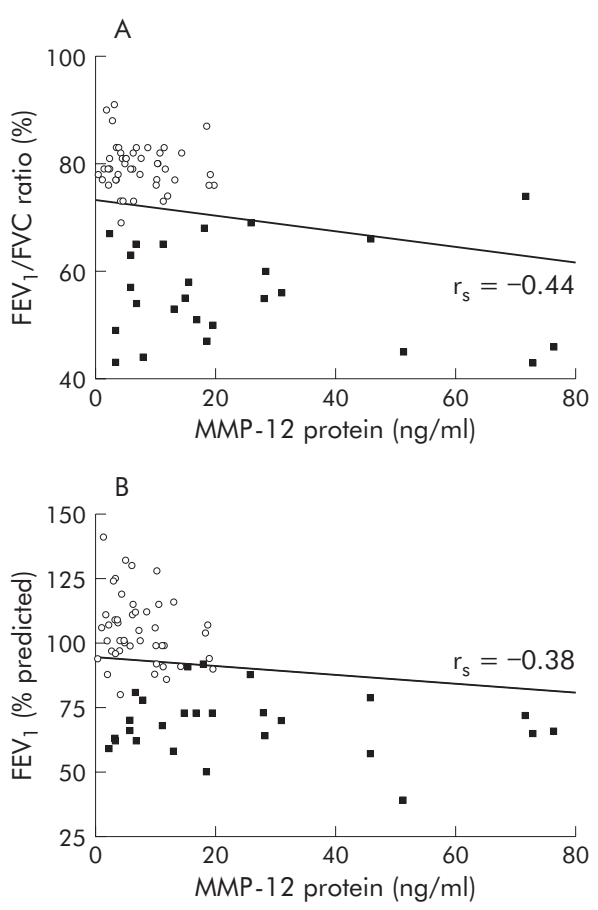

Figure 6 Relation between MMP-12 protein levels in induced sputum and (A) $\mathrm{FEV}_{1} / \mathrm{FVC}$ ratio and (B) $\mathrm{FEV}$ (\% predicted). A significant inverse correlation was found for both FEV $1 / F V C$ ratio $\left(r_{s}=-0.44\right.$, $\mathrm{p}=0.00007)$ and $\mathrm{FEV}_{1} \%$ predicted $\left(r_{\mathrm{s}}=-0.38, \mathrm{p}=0.0008\right)$ for all subjects. COPD patients $(n=28) ; \bigcirc$, controls (healthy smokers, never smokers, former smokers; $n=48$ ). 


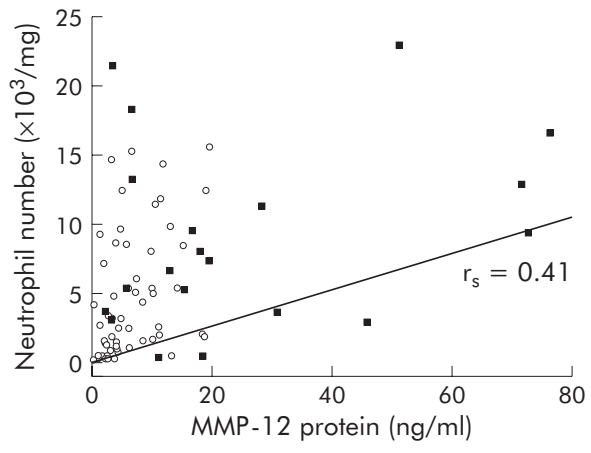

Figure 7 Relation between MMP-12 protein levels and absolute neutrophil number in induced sputum. A significant positive correlation $\left(r_{s}=0.41, p=0.0004\right)$ was found between the absolute neutrophil number and MMP-12 in induced sputum for all subjects. a, COPD patients ( $n=28) ; \bigcirc$, controls (healthy smokers, never smokers, former smokers; $\mathrm{n}=48$ ).

lung. In induced sputum, MMP-12 levels did not correlate with the absolute number of macrophages. However, as already suggested by other authors, ${ }^{4}$ it is probably macrophage activation rather than the macrophage number that accounts for the increased total secretion of MMP-12.

Only a few data are available on the role of MMP-12 in COPD in human subjects. Montaño and colleagues ${ }^{25}$ studied MMP activity and expression in alveolar macrophages from patients with COPD; they found increased macrophage elastolytic activity in COPD patients and suggest that this enzymatic activity corresponds to MMP-12. Recent work from Molet and colleagues ${ }^{13}$ demonstrated enhanced MMP12 expression in BAL fluid and in bronchial biopsies from COPD patients compared with controls (a heterogeneous group of smokers and non-smokers). As mentioned earlier, Grumelli et al showed that IP-10 and MIG, released by lung lymphocytes, upregulated MMP-12 secretion by lung macrophages and that this is mediated by the CXCR3 chemokine receptor on macrophages. Moreover, they showed by immunohistochemistry that lung macrophages from patients with emphysema express MMP-12 while lung macrophages from healthy smokers (without emphysema) do not. ${ }^{21}$

Our results show, for the first time, increased MMP-12 protein levels and MMP-12 related enzymatic activity in induced sputum from patients with COPD compared with smokers without obstructive airway disease, former smokers and never smokers. Altogether, these data provide increasing evidence that MMP-12 is involved in the development of COPD in human subjects, and thus confirm the earlier findings from animal models. It is also clear that MMP-12 could be an interesting target for new pharmacological treatments for COPD. In mice, a potent synthetic inhibitor of both human and murine MMP-12 (RS-113456) prevented progression of emphysema in smoke exposed animals. ${ }^{26}$ These promising preclinical results, however, need to be confirmed in well designed clinical trials in human patients.

\section{ACKNOWLEDGEMENTS}

This work is dedicated to the memory of Professor Dr Romain Pauwels who passed away on 3 January 2005. The authors thank A Neessen, I De Borle, M Mouton, F Perin-Rasquin and S Verschraegen for their technical contribution to this work.

\section{Authors' affiliations}

I K Demedts, G F Joos, R A Pauwels, G G Brusselle, Department of Respiratory Diseases, Ghent University Hospital, Ghent, Belgium A Morel-Montero, Immunotech, Beckman Coulter, Marseille, France S Lebecque, Y Pacheco, Service de Pneumologie, CHU-Lyon, France
D Cataldo, Department of Pneumology, University of Liege and CHU Liege, Liege, Belgium

This work was supported by the Fund for Scientific Research in Flanders (FWO Vlaanderen, Research Projects G.0011.03 and G.0343.01N) and by project grant 01251504 from the Concerted Research Initiative of the Ghent University. ID is a doctoral research fellow of the Fund for Scientific Research in Flanders (FWO Vlaanderen).

Competing interests: none declared.

\section{REFERENCES}

1 Pauwels RA, Buist AS, Calverley PM, et al. Global strategy for the diagnosis, management, and prevention of chronic obstructive pulmonary disease. NHLBI/WHO Global Initiative for Chronic Obstructive Lung Disease (GOLD) Workshop summary. Am J Respir Crit Care Med 2001;163:1256-76.

2 Barnes PJ, Shapiro SD, Pauwels RA. Chronic obstructive pulmonary disease: molecular and cellular mechanisms. Eur Respir J 2003;22:672-88.

3 Parks WC, Wilson CL, Lopez-Boado YS. Matrix metalloproteinases as modulators of inflammation and innate immunity. Nat Rev Immunol 2004:4:617-29.

4 Churg A, Wang RD, Tai H, et al. Macrophage metalloelastase mediates acute cigarette smoke-induced inflammation via tumor necrosis factor-alpha release. Am J Respir Crit Care Med 2003;167:1083-9.

5 Banda MJ, Clark EJ, Werb Z. Limited proteolysis by macrophage elastase inactivates human alpha 1-proteinase inhibitor. J Exp Med 1980;152:1563-70.

6 Sires UI, Murphy G, Baragi VM, et al. Matrilysin is much more efficient than other matrix metalloproteinases in the proteolytic inactivation of alpha 1-antitrypsin. Biochem Biophys Res Commun 1994;204:613-20.

7 Desrochers PE, Jeffrey JJ, Weiss SJ. Interstitial collagenase (matrix metalloproteinase-1) expresses serpinase activity. J Clin Invest 1991;87:2258-65.

8 Russell RE, Culpitt SV, DeMatos C, et al. Release and activity of matrix metalloproteinase- 9 and tissue inhibitor of metalloproteinase- 1 by alveolar macrophages from patients with chronic obstructive pulmonary disease. Am J Respir Cell Mol Biol 2002;26:602-9.

9 Shapiro SD, Kobayashi DK, Ley TJ. Cloning and characterization of a unique elastolytic metalloproteinase produced by human alveolar macrophages. J Biol Chem 1993;268:23824-9.

10 Hautamaki RD, Kobayashi DK, Senior RM, et al. Requirement for macrophage elastase for cigarette smoke-induced emphysema in mice. Science 1997;277:2002-4.

11 Gronski TJ Jr, Martin RL, Kobayashi DK, et al. Hydrolysis of a broad spectrum of extracellular matrix proteins by human macrophage elastase. J Biol Chem 1997;272:12189-94.

12 Joos $L, H e ~ J Q$, Shepherdson $M B$, et al. The role of matrix metalloproteinase polymorphisms in the rate of decline in lung function. Hum Mol Genet 2002;11:569-76.

13 Molet S, Belleguic $\mathrm{C}$, Lena $\mathrm{H}$, et al. Increase in macrophage elastase (MMP12 ) in lungs from patients with chronic obstructive pulmonary disease. Inflamm Res 2005;54:31-6.

14 Pizzichini E, Pizzichini MM, Leigh R, et al. Safety of sputum induction. Eur Respir J Supp/ 2002;37:9-18s.

15 Efthimiadis A, Spanevello A, Hamid Q, et al. Methods of sputum processing for cell counts, immunocytochemistry and in situ hybridisation. Eur Respir J Suppl 2002;37:19-23s.

16 Valladeau J, Duvert-Frances V, Pin JJ, et al. The monoclonal antibody DCGM4 recognizes Langerin, a protein specific of Langerhans cells, and is rapidly internalized from the cell surface. Eur J Immunol 1999;29:2695-704.

17 Gibbs DF, Warner RL, Weiss SJ, et al. Characterization of matrix metalloproteinases produced by rat alveolar macrophages. Am J Respir Cell Mol Biol 1999;20:1136-44.

18 Morris DG, Huang X, Kaminski N, et al. Loss of integrin alpha(v)beta6mediated TGF-beta activation causes MMP-12 dependent emphysema. Nature 2003;422:169-73.

19 Zheng T, Zhu Z, Wang Z, et al. Inducible targeting of IL-13 to the adult lung causes matrix metalloproteinase- and cathepsin-dependent emphysema. J Clin Invest 2000;106:1081-93.

20 Wang $Z$, Zheng $T$, Zhu Z, et al. Interferon gamma induction of pulmonary emphysema in the adult murine lung. J Exp Med 2000;192:1587-600.

21 Grumelli S, Corry DB, Song LZ, et al. An immune basis for lung parenchymal destruction in chronic obstructive pulmonary disease and emphysema. PLoS Med 2004; 1 :e8.

22 Lavigne MC, Thakker P, Gunn J, et al. Human bronchial epithelial cells express and secrete MMP-12. Biochem Biophys Res Commun 2004;324:534-46.

23 Lavigne MC, Eppihimer MJ. Cigarette smoke condensate induces MMP-12 gene expression in airway-like epithelia. Biochem Biophys Res Commun 2005;330: 194-203.

24 Le Naour F, Hohenkirk L, Grolleau A, et al. Profiling changes in gene expression during differentiation and maturation of monocyte-derived dendritic cells using both oligonucleotide microarrays and proteomics. J Biol Chem 2001;276:17920-31.

25 Montaño M, Beccerril C, Ruiz V, et al. Matrix metalloproteinases activity in COPD associated with wood smoke. Chest 2004; 125:466-72.

26 Martin RL, Shapiro SD, Tong SE, et al. Macrophage metalloelastase inhibitors. In: Hansell TT, Barnes PJ, eds. New drugs for asthma, allergy and COPD. Volume 31. Progress in Respiratory Research. Basel, Switzerland: Karger, 2001:177-80. 